\title{
Can negative emotions increase students' plagiarism and cheating?
}

\author{
Isabeau K. Tindall ${ }^{1,2+}$, Kit Wing Fu ${ }^{3+}$, Kell Tremayne ${ }^{3}$ and Guy J. Curtis ${ }^{1 *}$ (D)
}

\author{
*Correspondence: guy.curtis@uwa. \\ edu.au \\ ${ }^{\dagger}$ Isabeau K. Tindall and Kit Wing Fu \\ are joint first authors and \\ contributed equally to this work. \\ ${ }^{1}$ University of Western Australia, \\ School of Psychological Science, \\ Crawley, Australia \\ Full list of author information is \\ available at the end of the article
}

\begin{abstract}
The challenges of higher education can be stressful, anxiety-producing, and sometimes depressing for students. Such negative emotions may influence students' attitudes toward assessment, such as whether it is perceived as acceptable to engage in plagiarism. However, it is not known whether any impact of negative emotions on attitudes toward plagiarism translate into actual plagiarism behaviours. In two studies conducted at two universities (Study $1 N=718$; Study $2 N=490$ ), we examined whether negative emotionality influenced plagiarism behaviour via attitudes, norms, and intentions as predicted by the theory of planned behaviour. In both studies, negative affect predicted plagiarism intentions mediated by perceived norms, and intentions predicted plagiarism behaviour. These findings suggest that students' negative emotionality is a risk for plagiarism engagement and that higher education institutions should support students' emotional well-being, especially regarding assessment practices.
\end{abstract}

Keywords: Plagiarism, Academic integrity, Negative emotions, Attitudes, TPB

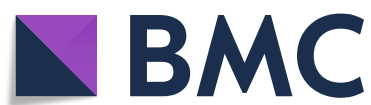

(c) The Author(s). 2021 Open Access This article is licensed under a Creative Commons Attribution 4.0 International License, which permits use, sharing, adaptation, distribution and reproduction in any medium or format, as long as you give appropriate credit to the original author(s) and the source, provide a link to the Creative Commons licence, and indicate if changes were made. The images or other third party material in this article are included in the article's Creative Commons licence, unless indicated otherwise in a credit line to the material. If material is not included in the article's Creative Commons licence and your intended use is not permitted by statutory regulation or exceeds the permitted use, you will need to obtain permission directly from the copyright holder. To view a copy of this licence, visit http://creativecommons.org/licenses/by/4.0/. The Creative Commons Public Domain Dedication waiver (http://creativecommons.org/publicdomain/zero/1.0/) applies to the data made available in this article, unless otherwise stated in a credit line to the data. 
question, then, is whether and how the negative emotions that students experience influence their likelihood of engaging in misconduct during academic assessment.

The only quantitative evidence, of which we are aware, directly linking negative emotions to academic misconduct is the study by Karim et al. (2009), which found that students' trait levels of neuroticism (a personality-based tendency to experience anxiety and low mood) were positively correlated with their engagement in internet-facilitated plagiarism (copying material from the internet verbatim or paraphrasing it without acknowledgment). More recently, Ives (2020) asked participants to rate 23 possible reasons for cheating on assignments. Feeling anxious or depressed were among the most strongly-endorsed reasons for cheating. In addition, Fu and Tremayne (2021) and Tindall and Curtis (2020) found that negative emotionality predicted more favourable attitudes toward plagiarism. This relationship between negative emotionality and attitudes was significant even when controlling for demographic factors that predicted engagement in plagiarism and cheating (e.g. age and gender; Jiang et al., 2013). The relationship found between students' emotions and their attitudes is consistent with a large body of research indicating that affective states can bias people's attitudes toward a range of issues (e.g. Forgas and Moylan (1987)). Importantly, negative emotions may lead to more positive attitudes in some situations (Ciarrochi and Forgas 1999).

Although Fu and Tremayne (2021) and Tindall and Curtis (2020) found a connection between negative emotionality and positive attitudes toward plagiarism, it has long been known in psychology that attitudes do not necessarily predict behaviour (Kraus 1995). In fact, one of the classic studies in psychology demonstrating the potential disconnection between attitudes and behaviours showed that students' cheating on selfscored tests within a university class was unrelated to their attitudes towards cheating (Corey 1937). However, well-established theoretical models have since been developed that suggest when and how attitudes will influence behaviour.

A prominent pair of theories connecting attitudes and behaviours are the theory of reasoned action (Fishbein 1979) and the theory of planned behaviour (TPB; Ajzen 1991). The theory of reasoned action states that attitudes combine with perceived social norms to predict intentions, and intentions then predict behaviour (Fishbein 1979). The TPB differs from the theory of reasoned action only in that perceived controllability of behaviour is added as an additional predictor of intentions. This perceived controllability of behaviour may be expressed as people's perception that they can successfully engage in the behaviour that they intend to and/or their perception that they can use self-control to stop themselves engaging in a behaviour that they would rather avoid (Wolfe and Higgins 2008).

In a recent review, Moss et al. (2018), found that the predictive factors in the TPB, i.e., attitudes, perceived norms, and perceived behavioural control, can predict plagiarism. Moreover, in research on academic assessment behaviour, several studies indicate that the TPB provides a valuable model for predicting students' engagement in plagiarism (e.g. Alleyne and Phillips 2011; Curtis et al. 2018; Uzun and Kilis 2020). Thus, the TPB provides a conceptual bridge between students' plagiarism attitudes and plagiarism behaviour. We can, therefore, potentially extend this bridge to consider how students' negative emotions may influence plagiarism behaviour via the effect of these emotions on their attitudes and perceptions of norms. 
As we noted, recent research suggests that negative emotions are related to more positive plagiarism attitudes, i.e. perceiving plagiarism as more acceptable (Fu and Tremayne, 2021; Tindall and Curtis 2020). This recent research also suggested that negative emotionality was related to perceiving plagiarism as more common, i.e. stronger subjective plagiarism norms. Importantly, however, that research did not examine whether the connection between emotionality, plagiarism attitudes, and subjective plagiarism norms translated into a connection with plagiarism behaviours.

More broadly, research using the TPB as a model of behavioural prediction has neglected the potential for emotions to influence the factors included in this model (Schwarz 1997). Because the theory of reasoned action and the TPB specify that attitudes influence behaviour via conscious intentions, it is clear that these theories assume conscious direction of behaviour. However, non-conscious and pre-conscious neurological and psychological processes usually precede, and sometimes unconsciously bias, what appears to people as consciously-directed actions (Wegner 2002). Affective states, in particular, can bias judgments and decisions without people being aware of them (Curtis and Locke 2007). Beyond this, when people try to think more deeply to overcome the potentially-biasing effects of emotions, such effortful thought can have the ironic effect of exacerbating the impact of emotions on judgments and behaviours (Forgas 1995). Given the above, we would expect, sequentially, for emotions to predict plagiarism attitudes (and other perceptions such as subjective norms and self-control) before attitudes predict intentions.

Given the under-examined role of emotion in the theory of reasoned action and the $\mathrm{TPB}$, in addition to the literature that suggests that plagiarism attitudes are related to negative emotions, we conducted two studies that examined whether negative emotions predicted plagiarism behaviour in the context of these theories.

\section{The present studies}

In Study 1, we applied the theory of reasoned action, and in Study 2 we applied a modified TPB, to predict engagement in plagiarism. The modified theory of reasoned action in Study 1, added negative affect as a potential predictor of attitudes and subjective norms. The modification to the TPB in Study 2 added negative affect as a potential predictor of attitudes, subjective norms, and controllability of behaviour. In addition, perceived behavioural control was replaced with self-control (see Fig. 1). As Curtis et al. (2018) argued, and demonstrated in their research, replacing perceived behavioural control with self-control allows the TPB to better represent the theoretically-expected predictors of unethical behaviour (e.g. Gottfredson and Hirschi 1990). Thus, as per Fig. 1 (below), negative emotionality was measured along with attitudes toward plagiarism, subjective plagiarism norms, self-control (in Study 2 only), intentions to plagiarise, and plagiarism behaviour.

We predicted that:

H1. Negative affect would predict plagiarism intentions mediated by positive attitudes toward plagiarism, subjective plagiarism norms, and, in Study 2, self-control.

H2. Plagiarism intentions would predict plagiarism behaviour. 


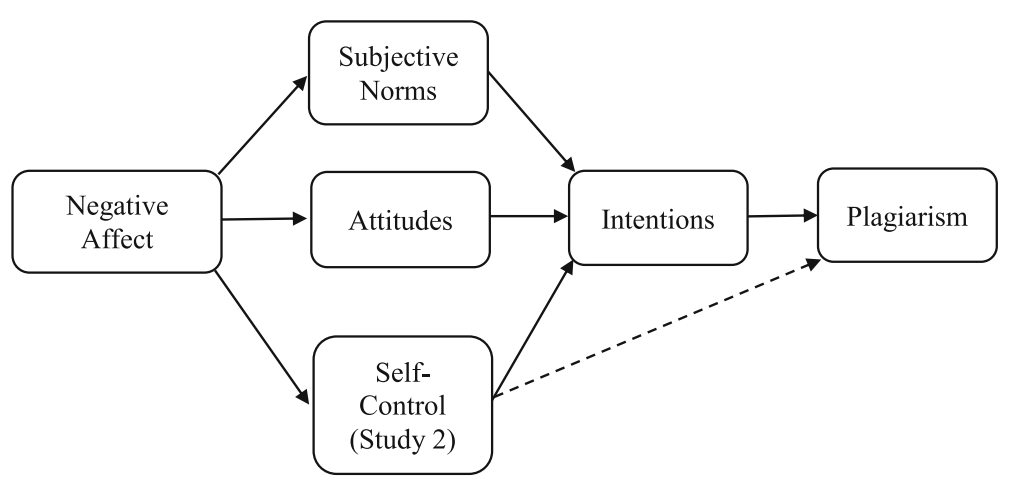

Fig. 1 Modified Theory of Planned Behaviour (Curtis et al. 2018) with negative affect added preceding the TPB predictors of intentions

Study 1

\section{Materials and methods}

\section{Participants and sampling procedure}

Ethical approval to undertake this study was obtained from the Murdoch University Human Research Ethics Committee. A total of 1077 university students took part in this study. Two participants did not give consent for their data to be used, three participants were under 18, and 259 participants were removed due to not fully completing all surveys. Fourteen participants who took over $24 \mathrm{~h}$ to complete the survey and seven who spent less than 2 seconds per question (Huang et al. 2012) were also removed. Lastly, 74 duplicate responses were excluded. Subsequently, a final sample size of 718 participants (females: $N=574, M_{\text {age }}=25.03, S D=8.88$; range $=18-64$ ) were included. The students were mainly white/Caucasian (79.8\%) and Asian (11.6\%).

The measures used in this study were completed online via Qualtrics. Participants also completed other measures that were used as pre-screening for another study and are, therefore, not reported here. Informed consent was obtained from students before they commenced the survey. The questionnaires were presented in a random order for each participant. Participants were recruited for this study through the Murdoch University research participant database, flyers posted around the university, and through university social media pages. Completion of the questionnaires took approximately 30 $\min$.

\section{Measures}

Attitudes toward plagiarism questionnaire (ATP; Mavrinac et al. 2010)

The ATP is a self-report questionnaire consisting of 29 items rated on a 5-point Likert scale from 1 (strongly disagree), to 5 (strongly agree). The scale included three subscales with items related to positive attitudes, negative attitudes, and subjective norms toward plagiarism. An example items from the positive attitudes toward plagiarism subscale is "I could not write a scientific paper without plagiarising". Higher values indicated an increased positive attitude toward plagiarism. Acting on recommendations from Tindall and Curtis (2020), item 24 from the subjective norms toward plagiarism subscale was reverse scored and the negative attitudes scale was omitted because of poor internal 
consistency. The positive attitude toward plagiarism and subjective norms toward plagiarism subscales of this questionnaire have shown sound internal consistency and reliability within graduate and undergraduate student populations; positive attitudes, $\alpha=$ .80; and subjective norms toward plagiarism, $\alpha=.76$ (Mavrinac et al. 2010; Tindall and Curtis 2020).

Plagiarism intentions and behaviour scale (Curtis et al. 2018; Maxwell et al. 2008;

Zafarghandi et al. 2012)

Three plagiarism scenarios used in Curtis et al. (2018), originally drawn from a sample of eight scenarios used in the study by Zafarghandi et al. (2012), were presented. Participants were presented with hypothetical scenarios representing sham paraphrasing, illicit paraphrasing, and sham primary citation. For example, for illicit paraphrasing, participants were shown a scenario stating that "A student reads some information from a book. The student then paraphrases the information and puts it into their assignment without acknowledging the source of the information". Participants were then asked "How often have you done something similar to this in the past?" (behaviour) and to indicate: 1 (never) to 5 (always); and "How likely are you to do something like this in the future?" (intention): 1 (very unlikely) to 5 (very likely). The mean behaviour and intentions toward plagiarism across the three scenarios were calculated for each participant.

\section{Positive and negative affect schedule-X (PANAS-X; Watson and Clark 1994)}

The PANAS- $X$ is a self-report questionnaire examining negative and positive affect rated on a 5-point Likert scale from 1 (very slightly, or not at all) to 5 (extremely). An adapted version of this scale (see Church et al. 2014) was used in this study, with 10 items measuring negative affect (four items from the Sadness subscale and six from the General Negative Affect scale) and 10 items measuring positive affect (four items from the Joviality subscale and six from the General Positive Affect scale). Some examples of the emotional descriptors are "interested", "distressed", and "alert". Higher scores on the negative affect and positive affect subscales indicate higher negative affect and higher positive affect, respectively. For this study, only the negative affect subscale was examined. The adapted version used has shown sound internal consistency, negative affect $\alpha \geq .89$, and reliability in many populations (Church et al. 2014).

\section{Results}

\section{Data screening and analysis approach}

A serial mediation analysis was run using model 80 in the SPSS PROCESS 3.4 macro (Hayes 2017). A model with negative affect acting as the predictor and plagiarism behaviour as the outcome variable was calculated. Positive attitudes toward plagiarism and subjective norms toward plagiarism were entered as mediators, with these also acting as the predictor of another mediator: plagiarism intentions (see Fig. 2). Entering all the mediators into the model allows for concurrent examination of the effects, holds all other variables constant, and controls for all the mediators (Hayes 2017).

A $z$-score of \pm 3.29 was used for assessing univariate outliers (Field 2009), with responses from 6 participants removed. Three multivariate outliers were removed based 


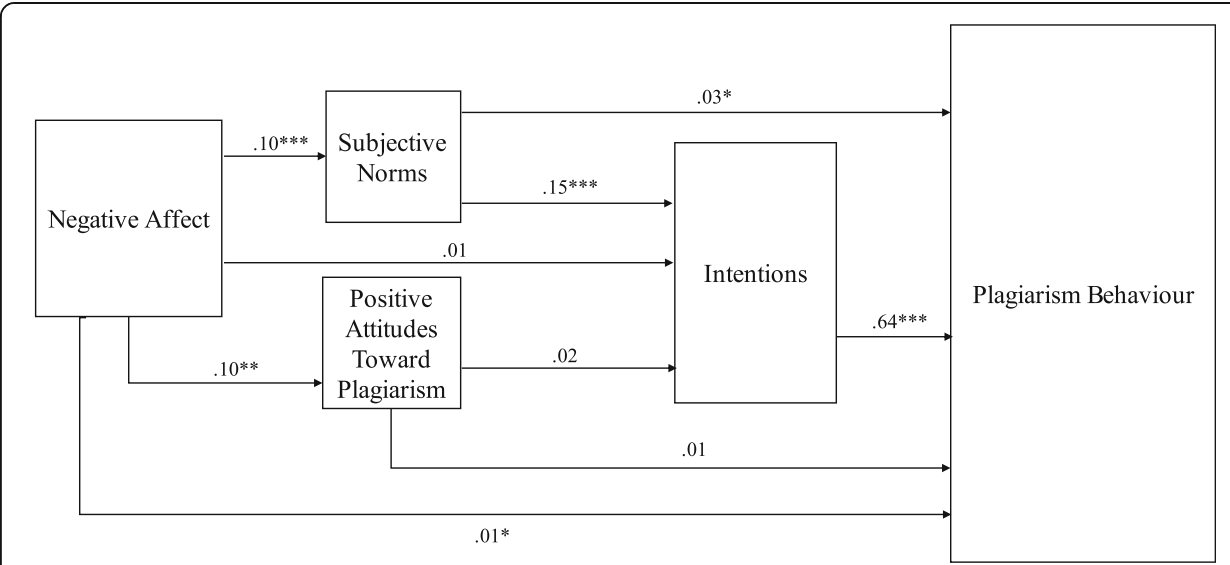

Fig. 2 Unstandardized regression coefficients for the mediation model between Negative Affect and Plagiarism Behaviour with Subjective Norms, Positive Plagiarism Attitudes and Plagiarism Intentions acting as mediators. Notes. $N=709 ;{ }^{*} p<.05,{ }^{* *} p<.01,{ }^{* * *} p<.001$

on a Mahalanobis distance significance value of $p<.001$. Subsequently, the final sample size included in analyses was 709 participants.

Data were normally distributed (skew: $-.08-.64$, kurtosis: $-.52-.00$ ), according to \pm 1 skew and kurtosis (Morgan et al. 2001). Further, no measures exceeded multicollinearity cut-offs according to tolerance $>0.1$ and VIF $<10$ (Hair et al. 1995), and all other statistical assumptions were satisfied. Descriptive statistics, internal consistencies, and correlations are presented in Table 1.

As shown in Fig. 2, a signficant positive indirect effect of negative affect on plagiarism behaviour was found, mediated by subjective norms toward plagiarism and plagiarism intentions (indirect effect $=0.01, \mathrm{SE}=.003 ; 95 \% \mathrm{CI}[0.004,0.016]$ ). Results indicated that higher negative affect was associated with higher subjective norms toward plagiarism $(\mathrm{B}=0.10 ; \mathrm{SE}=.03, \mathrm{t}=3.70, p<.001 ; 95 \% \mathrm{CI}[.048, .156])$ and higher subjective norms toward plagiarism were associated with higher plagiarism intentions $(B=0.15$, $\mathrm{SE}=.02, \mathrm{t}=8.86, p<.001 ; 95 \% \mathrm{CI}[.118, .186])$. An indirect effect of negative affect on plagiarism behaviour also occurred mediated by subjective norms toward plagiarism but not also mediated by intentions (indirect effect $=.003, \mathrm{SE}=.00$; 95\% CI [.0006, $.0 .007])$. Subjective norms toward plagiarism also predicted plagiarism behaviour $(\mathrm{B}=$ $.03, \mathrm{SE}=.01, \mathrm{t}=2.45, p=.015 ; 95 \% \mathrm{CI}[.006, .058])$.

Negative affect predicted positive attitudes toward plagiarism $(\mathrm{B}=0.10 ; \mathrm{SE}=.03, \mathrm{t}=$ $3.09, p=.002$; 95\% CI [.036, .163]). Interestingly, however, no indirect effect of negative affect on plagiarism behaviours via positive attitudes toward plagiarism and plagiarism

Table 1 Descriptive statistics, internal consistencies, and correlations - Study 1

\begin{tabular}{|c|c|c|c|c|c|c|}
\hline Measure & $M(S D)$ & $a$ & 1. & 2. & 3. & 4. \\
\hline 1. Negative Affect & $22.18(7.82)$ & .90 & & & & \\
\hline 2. Positive Attitudes Toward Plagiarism & $26.69(6.78)$ & .83 & $.12^{*}$ & & & \\
\hline 3. Subjective Norms Toward Plagiarism & $21.29(5.79)$ & .82 & $.14^{*}$ & $.74^{*}$ & & \\
\hline 4. Plagiarism Behaviour & $5.27(1.93)$ & .57 & $.14^{*}$ & $.38^{*}$ & $.46^{*}$ & \\
\hline 5. Plagiarism Intention & $5.20(2.04)$ & 65 & $.10^{*}$ & $.40^{*}$ & $.49^{*}$ & $.74^{*}$ \\
\hline
\end{tabular}


intentions was found (indirect effect $=0.00, \mathrm{SE}=.001 ; 95 \%$ CI $[-.0003,0.004]$ ). In addition, as shown in Fig. 2, positive attitudes toward plagiarism did not significantly predict either intentions or plagiarism behaviour.

Negative affect did not directly predict plagiarism intentions $(B=.01, S E=.01, t=$ $1.00, p=.317 ; 95 \%$ CI $[-.008, .026])$. However, negative affect did directly predict plagiarism behaviour $(B=.01, S E=.01, t=2.40, p=.017$; 95\% CI [.003, .027]). Further, the total effect of negative affect on plagiarism behaviour was also significant (total effect $=$ $0.02, S E=.01,95 \%$ CI $[.008, .034])$.

\section{Study 2}

Study 1 found that negative affect predicted plagiarism behaviour and was, sequentially, mediated by subjective plagiarism norms and intentions to plagiarize. Study 1 also found that negative affect predicted plagiarism behaviour directly in addition to the serial-mediation relationship. Including negative affect as a first step predictor of attitudes and norms was a modification of the theory of reasoned action. The TPB extends the theory of reasoned action by assessing perceptions of behavioural controllability. Thus, in Study 2, we added perceived behaviour controllability in the form of trait selfcontrol (as per Curtis et al. 2018), as a second-step predictor of intentions along with attitudes and norms (see Fig. 1).

In addition to adding self-control, in Study 2, we made two minor methodological changes to improve the reliability of the research design. First, although negative affect predicted plagiarism attitudes, unexpectedly attitudes did not subsequently predict intentions. Because of this, a fourth scenario was added to the measure of plagiarism intentions and behaviour to increase the content validity of these measures. Second, because relationships between self-report measures can be inflated when people try to present themselves in a socially-desirable way (Curtis et al. 2018), we added a socialdesirability measure in order to exclude students who showed a social-desirability pattern in their responses to the survey in the hope of reducing socially-desirable responding practices as a possible explanation of the results.

\section{Materials and methods}

\section{Participants and sampling procedure}

Ethical approval to undertake this study was obtained from the Western Sydney University Human Research Ethics Committee. A total sample of 1075 Western Sydney University undergraduate and postgraduate students commenced the online survey after being recruited through the university's Psychology Research Portal, social media, posters, flyers, and lecture campaigns. Participants recruited through the Psychology Research Portal completed the survey in a classroom on a personal electronic device and were awarded course credits for their participation. Participant information for credit was collected on a slip of paper that was placed in a box to ensure completely anonymous data collection. The participants recruited through all other methods were entered into a draw for a \$100 VISA gift card as an incentive and were provided the details and a link to enter the draw at the end of the survey.

As in Study 1, Qualtrics was used to present the survey online. To control for any order effects, the questions in each questionnaire and the order of appearance of the 
self-control scale and the PANAS were randomised. Furthermore, to control for any alterations in mood caused by completing these two scales, the attitudes toward plagiarism questionnaire was randomised to come either before or after these scales. The plagiarism intentions and behaviour scale and demographics were placed at the end of the survey.

After data collection, 455 participants were removed due to not fully completing all surveys. One case was removed as the participant was under 16 years old. Four participants who finished the survey in under 7 minutes (under 2 seconds per question; Huang et al., 2012) and seven participants who took more than $24 \mathrm{~h}$, were deleted. Then, 75 duplicate responses (based on IP addresses) were excluded. Finally, 43 cases were eliminated due to scores that fell outside the acceptable range on the Constructive Thinking Inventory's Defensiveness Scale, which indicated socially-desirable responding (Epstein 2001). These exclusions resulted in a final sample size of 490 (females $=374$; $M_{\text {age }}=22.53, S D=6.17$, range $\left.=16-64\right)$. The top three nationalities of participants were: Australian 71.8\%, Filipino 2.7\%, and Chinese, 2.5\%.

\section{Measures}

Attitudes toward plagiarism questionnaire (ATP; Mavrinac et al. 2010)

This is identical to the scale used in Study 1, with only the positive attitudes toward plagiarism and subjective norms toward plagiarism subscales used.

Plagiarism intentions and behaviour scale (Curtis et al. 2018; Maxwell et al., 2008;

Zafarghandi et al. 2012)

This measure was identical to Study 1, except that a fourth plagiarism scenario was added. In addition to sham paraphrasing, illicit paraphrasing, and sham primary citation, students were presented with a scenario representing copying the structure of another students' work and presenting it as their own (Zafarghandi et al. 2012).

Positive and negative affect schedule (PANAS; Watson et al. 1988)

This 20-item scale is similar to the PANAS-X (Watson and Clark 1994) used in Study 1 except for seven words, such as "Distressed", "Guilty", and "Jittery", which were in the PANAS but not the PANAS-X. For this study, only the negative affect subscale was examined. The Negative Affect subscale was found to have good validity, and internalconsistency reliability, $\alpha \geq .84$ (Crawford and Henry 2004; Watson et al. 1988).

\section{Brief self-control scale (Tangney et al. 2004)}

This 13-item self-report questionnaire measures trait self-control. An example item is "I refuse things that are bad for me", and participants respond on a 5-point Likert scale from 1 (not at all) to 5 (very much). Nine items are reverse scored and this scale was found to have good validity among college students (De Ridder et al. 2012), good internal reliability and consistency ( $\alpha \geq .83$; Tangney et al. 2004), as well as reasonable test-retest reliability (.87; Tangney et al. 2004). 


\section{Lie scale (Epstein 2001)}

This 5-point Likert Scale is an 8-item self-report questionnaire and examines whether participants are likely to present themselves as unrealistically positive. It has been found to have sound reliability ( $\alpha \geq .76$; Ammerman et al. 2001). Participants were excluded from analyses if they were found to respond according to social desirability cut-offs defined by Epstein (2001).

\section{Results}

Data screening and analysis approach

As in Study 1, a serial mediation analysis was run using model 80 in the SPSS PROCESS 3.4 macro (Hayes 2017). As shown in Fig. 3, the model was identical to that analysed in Study 1 except that self-control was added as an additional step-two mediator.

The dataset included no missing data since only completed cases were used in the analysis. During data screening, a total of four univariate outliers (with $z$-scores at an excess of +3.29; Tabachnick and Fidell 2013) and six multivariate outliers were found and deleted. Additionally, multicollinearity cut-offs (tolerance $>0.1$ and VIF $<10$ ) were not exceeded (Hair et al. 1995). After the data screening, a sample of 480 was used in the mediation analysis. See Table 2 for scale means, standard deviations, and correlations for Study 2.

As shown in Fig. 3, the analysis indicated that negative affect directly predicted plagiarism behaviours and predicted plagiarism behaviour via several mediated pathways. First, as in Study 1, there was a significant indirect effect of negative affect on plagiarism behaviour through subjective norms toward plagiarism and intentions to plagiarize (indirect effect $=0.01, \mathrm{SE}=.004 ; 95 \% \mathrm{CI}[0.003,0.02]$ ). The direction of the effects indicated that more negative affect predicted higher subjective norms toward plagiarism $(\mathrm{B}=0.11 ; \mathrm{SE}=.03, \mathrm{t}=3.75, p=.002 ; 95 \% \mathrm{CI}[.04, .17])$ and higher subjective norms

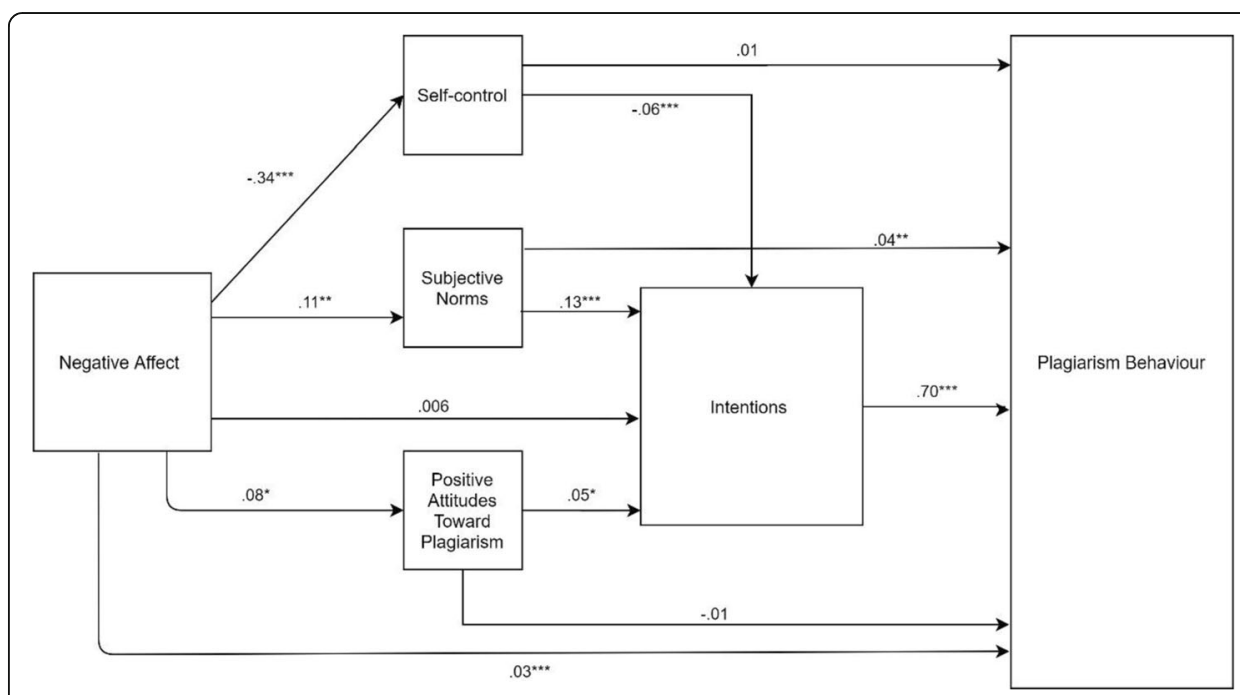

Fig. 3 Unstandardized regression coefficients for the serial mediation model between Negative Affect and Plagiarism Behaviour with Self-control, Subjective Norms, Positive Attitudes Toward Plagiarism and Plagiarism Intentions as mediators. Notes: $N=485 ;{ }^{*} p<.05,{ }^{* *} p<.01,{ }^{* * *} p<.001$ 
Table 2 Descriptive statistics, internal consistencies, and correlations - Study 2

\begin{tabular}{llllllll}
\hline Measure & M (SD) & a & 1. & 2. & 3. & 4. & 5. \\
\hline 1. Negative Affect & $19.20(8.23)$ & .90 & & & & & \\
2. Self-control & $38.25(8.41)$ & .83 & $-.33^{*}$ & & & \\
3. Positive Attitudes Toward Plagiarism & $28.61(7.15)$ & .82 & .12 & $-.21^{*}$ & & \\
4. Subjective Norms Toward Plagiarism & $21.71(6.09)$ & .81 & $.14^{*}$ & $-.27^{*}$ & $.75^{*}$ & & \\
5. Plagiarism Intention & $7.23(2.80)$ & .65 & $.13^{*}$ & $-.29^{*}$ & $.37^{*}$ & $.42^{*}$ \\
6. Plagiarism Behaviour & $7.08(2.49)$ & .61 & $.20^{*}$ & $-.24^{*}$ & $.35^{*}$ & $.42^{*}$ & $.83^{*}$ \\
\hline$N=480 ;{ }^{*} p<.01$ & & & & & & &
\end{tabular}

toward plagiarism predicted more intentions to plagiarize $(\mathrm{B}=.13, \mathrm{SE}=.03, \mathrm{t}=4.37$, $p<.001 ; 95 \%$ CI $[.07, .18])$. Higher subjective norms toward plagiarism also predicted more plagiarism behaviour $(\mathrm{B}=.04, \mathrm{SE}=.02, \mathrm{t}=2.72, p=007$; $95 \% \mathrm{CI}[.01, .08])$. Moreover, stronger intention to plagiarize was also related to more plagiarism behaviour $(\mathrm{B}=0.70, \mathrm{SE}=.03, \mathrm{t}=27.65, p<0.001 ; 95 \% \mathrm{CI}[0.65,0.75])$. Mediation was also present in the relationship between negative affect and plagiarism behaviour, where subjective norms toward plagiarism was the sole mediator, bypassing intentions (indirect effect $=$ $.005, \mathrm{SE}=.002 ; 95 \% \mathrm{CI}[.001, .01])$.

Another result that was consistent with Study 1 was that there was a significant direct effect of negative affect on plagiarism behaviour $(B=.03, S E=.01, t=3.84, p<.001$; $95 \% \mathrm{CI}[.02, .05])$. The total effect of negative affect on plagiarism behaviour was also significant (total effect $B=0.06, S E=.01, t=4.56, p<.001$; $95 \% \mathrm{CI}[0.04,0.09]$ ) indicating that more negative affect is related to more plagiarism behaviour.

Negative affect also predicted more positive attitudes toward plagiarism $(B=0.08$, $S E=.04 t=2.09, p=.037 ; 95 \% \mathrm{CI}[.02, .17])$ and more positive attitudes toward plagiarism predicted stronger intentions to plagiarize $(B=0.05, S E=.02, t=2.03, p=.042$; $95 \%$ $\mathrm{CI}[.01, .10])$. Sequentially, more intentions to plagiarize also led to more plagiarism behaviours as outlined above. However, similarly to Study 1, positive attitudes toward plagiarism and plagiarism intentions together did not mediate the relationship between negative affect and plagiarism behaviour (indirect effect $=0.003, S E=.002$; $95 \%$ CI [$0.001,0.008]$ ). Additionally, positive attitudes toward plagiarism did not significantly predict plagiarism behaviour without going through plagiarism intentions $(B=-.01$, $S E=.01, t=-0.75, p=.454 ; 95 \% \mathrm{CI}[-.04, .02])$. Consequently, the indirect effect of negative affect on plagiarism behaviour through positive attitudes toward plagiarism alone was not significant (indirect effect $=-.001, S E=.001 ; 95 \% \mathrm{CI}[-.004, .001]$ ).

Self-control was the new variable added as a mediator in Study 2. Results revealed that there was a significant indirect effect of negative affect on plagiarism behaviour mediated by self-control and plagiarism intentions (indirect effect $=0.01, \mathrm{SE}=.004 ; 95 \%$ $\mathrm{CI}[0.01,0.02])$. The analysis indicated that more negative affect predicted lower selfcontrol $(\mathrm{B}=-0.34, \mathrm{SE}=.04, \mathrm{t}=7.69, \mathrm{p}<.001 ; 95 \% \mathrm{CI}[-.43,-.25])$ and lower selfcontrol predicted more intentions to plagiarize $(\mathrm{B}=-.06, \mathrm{SE}=.01 ; \mathrm{t}=-4.04, \mathrm{p}<.001$; $95 \%$ CI $[-.09,-.03])$. In turn, more intentions to plagiarize predicted more plagiarism behaviour. However, negative affect was not indirectly related to plagiarism behaviour through self-control alone (indirect effect $=-.004, \mathrm{SE}=.003 ; 95 \%$ CI $[-0.01,0.001]$ ). Additionally, self-control alone was not found to be a significant predictor of plagiarism behaviour $(\mathrm{B}=.01, \mathrm{SE}=.01, \mathrm{t}=1.44, p=.150$; 95\% CI $[-.004, .03])$. 
Finally, mediation was not evident in the relationship between negative affect and plagiarism behaviour through plagiarism intentions (indirect effect $=.004, S E=.01 ; 95 \% \mathrm{CI}$ $[-.02, .02])$, as negative affect did not significantly predict plagiarism intentions $(B=.01$, $S E=.01, t=.42, p=.676$; $95 \%$ CI $[-.02, .04])$.

\section{Discussion}

We predicted (H1) that negative affect would predict plagiarism intentions mediated by positive attitudes toward plagiarism, subjective plagiarism norms, and, in Study 2, selfcontrol. In both Studies 1 and 2, negative affect predicted subjective plagiarism norms, which predicted plagiarism intentions. Furthermore, when self-control was measured in Study 2, it also mediated the relationship between negative affect and plagiarism intentions. In addition to these findings, as predicted ( $\mathrm{H} 2)$, plagiarism intentions predicted plagiarism behaviour in both studies. Interestingly, however, in both studies, there was no indirect effect of negative affect on plagiarism behaviour through positive plagiarism attitudes and intentions. Moreover, in both studies, negative affect directly predicted plagiarism behaviour in addition to its prediction of the mediators.

The results of the present studies are an incremental advance on previous findings, which indicated that negative affect predicts plagiarism attitudes and subjective norms (Fu and Tremayne 2021; Ives 2020; Tindall and Curtis 2020). In particular, the present studies demonstrated that negative affect predicts plagiarism intentions and plagiarism behaviour; partly mediated by self-control and perceived norms. Previous studies, such as Fu and Tremayne's (2021) and Tindall and Curtis's (2020), had not examined plagiarism behaviour, and it thus remained an open question whether students' negative emotions were related to academic integrity breaches. Although Karim et al. (2009) had linked trait neuroticism with plagiarism behaviour, they did not assess whether there was a relationship between current emotional states and academic misconduct, or whether the neuroticism-plagiarism relationship was mediated by attitudes, norms, selfcontrol, or intentions.

The questions examined in the present studies were also interesting theoretically, given that the connection between attitudes and behaviour can be tenuous (Kraus 1995). Moreover, authors have argued that affect should be considered in predicting unethical behaviours (van Gelder 2013) and components of the TPB (Schwarz 1997). In addition, the research was interesting practically, because if negative affect was unrelated to plagiarism behaviour, there would be little pragmatic impact on academic integrity of ameliorating these emotions among students. However, the relationship between negative emotionality and plagiarism behaviour suggests potential interventions. Therefore, the findings of the current studies are valuable on two fronts, theoretical and practical.

\section{Theoretical implications}

In Studies 1 and 2, subjective norms both directly and indirectly predicted plagiarism behaviours via intentions. The relationship between intentions and plagiarism behaviour supports the growing body of research (e.g. Alleyne and Phillips 2011; Curtis et al. 2018) utilising the TPB (Ajzen 1991) when explaining engagement in academic misconduct. The involvement of intentions in predicting plagiarism behaviour indicates that 
plagiarism can occur consciously, as intentions are, by definition, conscious plans (Curtis et al. 2018). However, the direct pathways found between negative affect and plagiarism behaviours, and between subjective norms and plagiarism behaviours - both bypassing intentions, also suggests that plagiarism may be influenced by factors that reside outside of students' conscious awareness (Curtis et al. 2018).

In criminological theories, it is often argued that conscious reasons people hold to justify behaviours are critical for explaining unethical conduct (e.g. Rundle et al. 2019). However, van Gelder (2013) argued that emotions, in addition to cognitions, may account for unethical decision-making. The impact of emotions on unethical decisions (i.e. plagiarism intentions and behaviour) observed in our studies lend further support to this perspective. Similarly, Schwarz (1997) contended that emotions may directly predict behaviour, bypassing attitudes and intentions in a TPB-based analysis, as observed in our study. Indeed, the capacity of emotions to directly predict academic misconduct behaviour may account for the surprising lack of an indirect effect of negative emotions on academic misconduct behaviour mediated by attitudes in our studies.

The finding of Study 2, that self-control predicted plagiarism intentions, which then predicted plagiarism behaviour, is also important theoretically. It was argued by Curtis et al. (2018) that self-control; specific to an individual's ability to stop themselves from engaging in plagiarism, can replace perceived behavioural control within the TPB. The findings of Study 2 adds support to this perspective and are also consistent with the General Theory of Crime (Gottfredson and Hirschi 1990), which states that unethical behaviours occur via an interplay between the opportunity to act unethically and deficits in self-control. Although our studies examined self-control, they did not examine opportunities to engage in academic misconduct. Nonetheless, from the General Theory of Crime, it can be suggested that self-control deficits attributable to negative emotions may not necessarily lead to academic misconduct if opportunities to engage in academic misconduct are limited, such as by assessment design.

\section{Practical implications}

The finding that negative affect was related to plagiarism behaviours, intentions, and plagiarism attitudes, and also self-control (in Study 2), is important practically to higher education teachers and policymakers. Interventions specific to individual-level treatment and organisational changes should be considered to reduce negative emotionality within these settings. Specifically, higher education providers should implement programs focusing on reducing mental health problems associated with negative affect, such as stress, anxiety, and depression (see Rith-Najarian et al. 2019). For instance, increasing access to counselling, stress management workshops, and educating students on coping skills might reduce negative emotionality (Rith-Najarian et al. 2019) and subsequently reduce plagiarism behaviours.

Broader organisational change should also be implemented to reduce negative emotionality. For example, heavily-weighted assessment items are associated with cheating (Bretag et al. 2019), and this may be because high-stakes assessments create negative emotionality such as stress. Thus, the impact of student stress on assessment design, weighting, and timing could be considered as a risk to academic integrity that may be mitigated via redesign. Similarly, students studying in their non-native language may be 
more likely to cheat (Bretag et al. 2019; Curtis et al. 2021), which may be partly attributable to the stresses of studying away from home and/or in another language. Thus, language support to non-native speakers may incidentally help with such stresses and consequentially mitigate some pressure to engage in academic misconduct.

Moreover, higher education institutions can also express support for academic integrity standards in words (e.g. honour codes) and actions (e.g. specific academic integrity education; e.g. Curtis et al. 2020), which will help set expected norms for students (Simola 2017). Such norms may also be reinforced by emphasising to students the potential impact of academic misconduct on the reputation of their qualifications. Additionally, considering the findings of Study 2, assessments and classroom activities should seek to foster students' self-control (e.g., Oaten and Cheng 2006).

\section{Limitations and future research}

The methods used in this paper relied on self-reports of academic misconduct. Recent research suggests that self-reports may underestimate the prevalence of academic misconduct (Curtis et al. 2021). However, other studies, such as Curtis et al. (2018), suggest that underreporting may change the "level" of observed misconduct, but not the relationship among variables such as attitudes, norms, intentions, and behaviour. Nonetheless, it is important to note that the average level of academic misconduct reported by students in our studies may be below the true figure.

In Study 1, there was no check on whether socially-desirable responding patterns could have influenced the results (Van de Mortel 2008). In Study 2, however, the potential impact of social-desirability bias on responses was minimised through the inclusion of the Constructive Thinking Inventory's Defensiveness Scale (Epstein 2001), which allowed for identification, and subsequent removal of people showing a sociallydesirable responding pattern. It is likely, that the impact of any socially-desirable responding bias in Study 1 was therefore minimal, as findings of Study 1 and 2 were consistent. Nevertheless, further research should continue to apply methods to minimise social desirability biases.

This paper focused on statistically predicting past plagiarism behaviours, rather than identifying potential future plagiarism. Although examining predictors of past plagiarism behaviour can inform interventions, preemptively predicting behaviour allows for eliminating plagiarism before it occurs. Therefore, additional studies should seek to experimentally predict future plagiarism behaviour from negative emotionality. This could be tested via an intervention-based experimental design, where interventions are set in place to deliberately reduce negative emotionality among students where impacts on academic integrity breaches are observed.

\section{Summary and conclusion}

Studies 1 and 2 sought to examine whether negative emotionality could predict plagiarism intentions, and subsequently plagiarism behaviour, when incorporated into the TBP (Ajzen 2001). In both studies, negative emotionality predicted plagiarism behaviour and plagiarism intentions through subjective plagiarism norms, and in Study 2, via self-control. In addition, negative emotionality directly predicted plagiarism behaviour. The findings of this study, therefore, both complement and extend past research. Our 
findings reinforce the importance of targeting negative emotionality within educational settings through interventions to reduce mental health problems and stresses on students. Furthermore, these findings imply that wider societal issues that may generally increase negative emotional experiences in students may have a flow-on effect to academic misconduct. Finally, we would urge higher education practitioners to consider the potential impact of stresses caused by assessment design and deadlines on their students as a potential risk factor that may contribute to academic misconduct.

\section{Acknowledgements}

We would like to thank the anonymous students who participated in our studies. Some data collected from the same sample of participants in the larger questionnaire they completed for Study 1 are published in Tindall and Curtis (2020) and Tindall et al. (2021). Some data collected from the same sample of participants in the larger questionnaire they completed for Study 2 is published in Curtis and Tremayne (2021).

\section{Authors' contributions}

All authors conceptualized the study, IT, KT, and KF collected data, IT and KF prepared the method and results sections of the manuscript, GC wrote the Introduction and Discussion. All authors reviewed and revised the draft manuscript.

\section{Funding}

This work was supported partly by an Australian Government Research Training Program (RTP) Scholarship awarded to IT.

\section{Availability of data and materials}

The data that support the findings of this study are available from the corresponding author upon reasonable request.

\section{Declarations}

\section{Competing interests}

The authors have no competing interests to declare in relation to the research reported in this paper.

\section{Author details}

${ }^{1}$ University of Western Australia, School of Psychological Science, Crawley, Australia. ${ }^{2}$ Murdoch University, Discipline of Psychology, Murdoch, Australia. ${ }^{3}$ Western Sydney University, School of Psychology, Penrith, Australia.

Received: 5 July 2021 Accepted: 16 October 2021

Published online: 06 December 2021

\section{References}

Ajzen I (1991) The theory of planned behavior. Organ Behav Hum Dec 50(2):179-211. https://doi.org/10.1016/0749-5978(91 )90020-T

Ajzen I (2001) Nature and operation of attitudes. Annu Rev Psycho 52(1):27-58. https://doi.org/10.1146/annurev.psych.52.1.27 Alleyne P, Phillips K (2011) Exploring academic dishonesty among university students in Barbados: an extension to the theory of planned behaviour. J Acad Ethics 9(4):323-338. https://doi.org/10.1007/s10805-011-9144-1

Ammerman RT, Lynch KG, Donovan JE, Martin CS, Maisto SA (2001) Constructive thinking in adolescents with substance use disorders. Psychology of addictive behaviors, 15(2):89-96. https://doi.org/10.1037/0893-164X.15.2.89

Backhaus IV, Varela AR, Khoo S, Siefken K, Crozier A, Begotaraj A, Fischer F, Wiehn J, Lanning BA, Lin P-H, Jang S-N, Monteiro LZ, Al-Smali A, La Torre G, Kawachi I (2020) Associations between social capital and depressive symptoms among college students in 12 countries: results of a cross-national study. Front Psychol 11(e644). https://doi.org/10.3389/fpsyg.2020. 00644

Bretag T, Harper R, Burton M, Ellis C, Newton P, Rozenberg P, Saddiqui S, van Haeringen K (2019) Contract cheating: a survey of Australian university students. Stud High Educ 44(11):1837-1856. https://doi.org/10.1080/03075079.2018.1462788

Church AT, Katigbak MS, Ibáñez-Reyes J, de Jesús V-FJ, Curtis GJ, Tanaka-Matsumi J, Cabrera HF, Mastor KA, Zhang H, Shen J, Locke KD, Alvarez JM, Ching CM, Ortiz FA, Simon J-YR (2014) Relating self-concept consistency to hedonic and eudaimonic well-being in eight cultures. J Cross-Cult Psychol 45(5):695-712. https://doi.org/10.1177/0022022114527347

Ciarrochi JV, Forgas JP (1999) On being tense yet tolerant: the paradoxical effects of trait anxiety and aversive mood on intergroup judgments. Group Dyn-Theo Res 3(3):227-238. https://doi.org/10.1037/1089-2699.3.3.227

Corey SM (1937) Professed attitudes and actual behavior. J Educ Psychol 28(4):271-280. https://doi.org/10.1037/h0056871

Cramer D, Donachie M (1999) Psychological health and change in closeness in platonic and romantic relationships. J Soc Psychol 139(6):762-767. https://doi.org/10.1080/00224549909598255

Crawford JR, Henry JD (2004) The positive and negative affect schedule (PANAS): construct validity, measurement properties and normative data in a large non-clinical sample. Brit J Clin Psychol 4(3):245-265. https://doi.org/10.1348/0144665031 752934

Curtis GJ, Cowcher E, Greene BR, Rundle K, Paull M, Davis MC (2018) Self-control, injunctive norms, and descriptive norms predict engagement in plagiarism in a theory of planned behavior model. J Acad Ethics 16(1):225-239. https://doi.org/1 $0.1007 /$ s10805-018-9309-2

Curtis GJ, Locke V (2007) Anxiety and impression formation: direct information rather than priming explains affect congruity. Cogn Emotion 21(7):1455-1469. https://doi.org/10.1080/02699930601134000 
Curtis GJ, McNeill M, Slade C, Tremayne K, Harper R, Rundle K, Greenaway R (2021) Moving beyond self-reports to estimate the prevalence of commercial contract cheating: an Australian study. Stud High Educ:1-13. https://doi.org/10.1080/03 075079.2021 .1972093

Curtis GJ, Slade C, Bretag T, McNeill M (2020) Developing and evaluating nationwide expert-delivered academic integrity workshops for the higher education sector in Australia. High Educ Res Dev:1-16. https://doi.org/10.1080/07294360.2021.1 872057

Curtis GJ, Tremayne K (2021) Is plagiarism really on the rise? Results from four 5-yearly surveys. Studies in Higher Education, 46(9):1816-1826. https://www.tandfonline.com/doi/full/10.1080/03075079.2019.1707792

de Ridder DTD, Lensvelt-Mulders G, Finkenauer C, Stok FM, Baumeister RF (2012) Taking stock of self-control: a meta-analysis of how trait self-control relates to a wide range of behaviors. Personal Soc Psychol Rev 16(1):76-99. https://doi.org/10.11 $77 / 1088868311418749$

Devlin M, Gray K (2007) In their own words: a qualitative study of the reasons Australian university students plagiarize. High Educ Res Dev 26(2):181-198. https://doi.org/10.1080/07294360701310805

Eisenberg D, Hunt J, Speer N (2013) Mental health in American colleges and universities: variation across student subgroups and across campuses. J Nerv Ment Dis 20(1):60-67. https://doi.org/10.1097/NMD.0b013e31827ab077

Epstein S (2001) Constructive thinking inventory: professional manual. Psychological Assessment Resources, Lutz

Field A (2009) Discovering Statistics Using SPSS, 3rd ed. London: Sage Publications Ltd

Fishbein M (1979) A theory of reasoned action: some applications and implications. Nebr Sym Motiv 27:65-116

Forgas JP, Moylan S (1987) After the movies: Transient mood and social judgments. Personality and social psychology bulletin 13(4):467-477. https://doi.org/10.1177/0146167287134004

Forgas J (1995) Mood and judgment: the affect infusion model (AIM). Psychol Bull 117(1):39-66. https://doi.org/10.1037/ 0033-2909.117.1.39

Fu KW, Tremayne KS (2021) Self-efficacy and self-control mediate the relationship between negative emotions and attitudes toward plagiarism. J Acad Ethics. https://doi.org/10.1007/s10805-021-09415-3

Gottfredson MR, Hirschi T (1990) A general theory of crime. Stanford University Press, Stanford

Hair JF, Anderson RE, Tatham RL, Black WC (1995) Multivariate data analysis. Englewood Cliffs, NJ: Prentice-Hall

Hayes AF (2017) Introduction to mediation, moderation, and conditional process analysis: a regression-based approach, 2nd edn. Guilford Publications, New York

Huang JL, Curran PG, Keeney J, Poposki EM, DeShon RP (2012) Detecting and deterring insufficient effort responding to surveys. J Bus Psychol 27(1):99-114. https://doi.org/10.1007/s10869-011-9231-8

Ives B (2020) Your students are cheating more than you think they are. Why? Educ Res 31(1):46-53

Jiang H, Emmerton L, McKauge L (2013) Academic integrity and plagiarism: a review of the influences and risk situations for health students. High Educ Res Dev 32(3):369-380. https://doi.org/10.1080/07294360.2012.687362

Karim NSA, Zamzuri NHA, Nor YM (2009) Exploring the relationship between internet ethics in university students and the big five model of personality. Comput Educ 53(1):86-93. https://doi.org/10.1016/j.compedu.2009.01.001

Kraus SJ (1995) Attitudes and the prediction of behavior: a meta-analysis of the empirical literature. Personal Soc Psychol Bull 21(1):58-75. https://doi.org/10.1177/0146167295211007

Larcombe W, Finch S, Sore R, Murray CM, Kentish S, Mulder RA, Lee-Stecum P, Baik C, Tokatlidis O, Williams DA (2016) Prevalence and socio-demographic correlates of psychological distress among students at an Australian university. Stud High Educ 41(6):1074-1091. https://doi.org/10.1080/03075079.2014.966072

Lodhia D (2018) More university students are cheating - but it's not because they're lazy. The Guardian, May 1. Retrieved June 15, 2020 from https://www.theguardian.com/education/2018/may/01/university-students-cheating-tuition-fees-jobsexams

Mavrinac M, Brumini G, Bilić-Zulle L, Petrovečki M (2010) Construction and validation of attitudes toward plagiarism questionnaire. Croat Med J 51(3):195-201. https://doi.org/10.3325/cmj.2010.51.195

Maxwell AJ, Curtis GJ, Vardanega L (2008) Does culture influence understanding and perceived seriousness of plagiarism? Int J Educ Integr 4(2):25-40. https://doi.org/10.21913/IJEl.v4i2.412

Morgan GA, Griego OV, Gloeckner GW (2001) SPSS for Windows: An introduction to use and interpretation in research. Mahwah: Lawrence Erlbaum.

Moss SA, White B, Lee J (2018) A systematic review into the psychological causes and correlates of plagiarism. Ethics Behav 28(4):261-283. https://doi.org/10.1080/10508422.2017.1341837

Oaten M, Cheng K (2006) Improved self-control: the benefits of a regular program of academic study. Basic Appl Soc Psychol 28(1):1-16. https://doi.org/10.1207/s15324834basp2801_1

Rickwood D, Telford N, O'Sullivan S, Crisp D, Magyar R (2016) National tertiary student wellbeing survey 2016. Headspace. Retrieved from https://www.headspace.org.au/assets/Uploads/headspace-NUS-Publication-Digital.pdf

Rith-Najarian LR, Boustani MM, Chorpita BF (2019) A systematic review of prevention programs targeting depression, anxiety, and stress in university students. J Affect Disord 257:568-584. https://doi.org/10.1016/j.jad.2019.06.035

Rundle K, Curtis GJ, Clare J (2019) Why students do not engage in contract cheating. Front Psychol 10(2229). https://doi.org/1 $0.3389 /$ fpsyg.2019.02229

Schwarz N (1997) Moods and attitude judgments: a comment on Fishbein and Middlestadt. J Consum Psychol 6(1):93-98. https://doi.org/10.1207/s15327663jcp0601_06

Simola S (2017) Managing for academic integrity in higher education: insights from behavioral ethics. Scholarship Teach Learn Psychol 3(1):43-57. https://doi.org/10.1037/stl0000076

Tabachnick BG, Fidell LS (2013) Using multivariate statistics 6th edn. Pearson Education, Harlow

Tangney JP, Baumeister RF, Boone AL (2004) High self-control predicts good adjustment, less pathology, better grades, and interpersonal success. J Pers 72(2):271-324. https://doi.org/10.1111/j.0022-3506.2004.00263.x

Tindall IK, Curtis GJ (2020) Negative emotionality predicts attitudes toward plagiarism. J Acad Ethics 18(1):89-102. https://doi. org/10.1007/s10805-019-09343-3

Tindall IK, Curtis G, Locke V (2021) Dimensionality and Measurement Invariance of the State-Trait Inventory for Cognitive and Somatic Anxiety (STICSA) and Validity Comparison with Measures of Negative Emotionality. Frontiers of Psychology, 12: 644889. https://doi.org/10.3389/fpsyg.2021.644889 
Uzun AM, Kilis S (2020) Investigating antecedents of plagiarism using extended theory of planned behavior. Comput Educ 144(103700):103700. https://doi.org/10.1016/j.compedu.2019.103700

Van de Mortel TF (2008) Faking it: social desirability response bias in self-report research. Aust J Adv Nurs 25(4):40-48

Van Gelder JL (2013) Beyond rational choice: the hot/cool perspective of criminal decision making. Psychol Crime Law 19(9): 745-763. https://doi.org/10.1080/1068316X.2012.660153

Watson D, Clark LA (1994) The PANAS-X: manual for the positive and negative affect schedule-expanded form. Ames, IA: The University of lowa

Watson D, Clark LA, Tellegen A (1988) Development and validation of brief measures of positive and negative affect: the PANAS scales. J Pers Soc Psychol 54(6):1063-1070. https://doi.org/10.1037/0022-3514.54.6.1063

Wegner DM (2002) The illusion of conscious will. MIT Press, Boston. https://doi.org/10.7551/mitpress/3650.001.0001

Wolfe SE, Higgins GE (2008) Self-control and perceived behavioral control: an examination of college student drinking. Appl Psychol Crim Just 4(1):108-133

Zafarghandi AM, Khoshroo F, Barkat B (2012) An investigation of Iranian EFL masters students' perceptions of plagiarism. Int J Educ Integr 8(2):69-85. https://doi.org/10.21913/JEl.v8i2.811

\section{Publisher's Note}

Springer Nature remains neutral with regard to jurisdictional claims in published maps and institutional affiliations.

\section{Ready to submit your research? Choose BMC and benefit from:}

- fast, convenient online submission

- thorough peer review by experienced researchers in your field

- rapid publication on acceptance

- support for research data, including large and complex data types

- gold Open Access which fosters wider collaboration and increased citations

- maximum visibility for your research: over 100M website views per year

At $\mathrm{BMC}$, research is always in progress. 